\title{
Overexpression of GAS6 Promotes Cell Proliferation and Invasion in Bladder Cancer by Activation of the PI3K/AKT Pathway
}

This article was published in the following Dove Press journal: OncoTargets and Therapy

\author{
Shiyu Mao' \\ Yuan $\mathrm{Wu}^{2}$ \\ Ruiliang Wang (D) \\ Yadong Guo' \\ Dexi $\mathrm{Bi}^{3}$ \\ Wenchao $\mathrm{Ma}^{2}$ \\ Wentao Zhang (D) \\ Junfeng Zhang ${ }^{1, *}$ \\ Yang Yan' \\ Xudong Yao (iD) ${ }^{1, *}$ \\ 'Department of Urology, Shanghai Tenth \\ People's Hospital, Tongji University \\ School of Medicine, Shanghai 200072, \\ People's Republic of China; ${ }^{2}$ Department \\ of Urology, Shanghai Tenth People's \\ Hospital, Anhui Medical University, Hefei \\ 230032, People's Republic of China; \\ ${ }^{3}$ Department of Pathology, Shanghai \\ Tenth People's Hospital, Tongji University \\ School of Medicine, Shanghai 200072, \\ People's Republic of China
}

*These authors contributed equally to this work

Correspondence: Junfeng Zhang; Xudong Yao

Department of Urology, Shanghai Tenth People's Hospital, Tongji University School of Medicine, Shanghai 200072,

People's Republic of China

Tel +8613817811836

Fax +86-2I-66305I58

Email zjfdipan@।26.com;

yaoxudong1967@I63.com
Background: Growth arrest-specific 6 (GAS6) is a secreted vitamin K-dependent protein abnormally expressed in various human tumor tissues and can activate the receptor Tyro3, Axl, and Mer to promote cancer cell proliferation and invasion. Until now, the role of GAS6 has been poorly understood in bladder cancer $(\mathrm{BCa})$.

Materials and Methods: Using bioinformatics analysis, we screened genes significantly associated with overall survival in BCa. The association between GAS6 and survival was evaluated by tissue microarray and IHC staining. We investigated the effect of GAS6 on the development of $\mathrm{BCa}$ through in vitro and in vivo experiments.

Results: Here, we report that GAS6 is highly expressed in bladder cancer and is significantly associated with tumor grade, T stage, and worse prognosis. We found that GAS6 depletion inhibited proliferation, migration, and invasion of $\mathrm{BCa}$ cells. In addition, bioinformatics analysis revealed that GAS6 may be involved in the regulation of PI3K-AKT signaling pathway by binding to receptor TAM and has a significant positive correlation with PI3K family gene expression. Furthermore, Western blot experiments have shown that GAS6 might modulate the PI3K-AKT signaling to regulate proliferation and invasion of BCa cells. Treatment of BCa cells with $\mathrm{SC79}$, an AKT activator, partially restored the effect of GAS6 silencing on cell proliferation and invasion.

Conclusion: The present study suggests that GAS6 may play a pivotal role in the development of $\mathrm{BCa}$ and may be a potential target for its treatment.

Keywords: bladder cancer, GAS6, proliferation, invasion, PI3K/AKT

\section{Background}

Bladder cancer (BCa) is the ninth most common cancer in males worldwide. ${ }^{1}$ Specifically, nearly $75 \%$ of $\mathrm{BCa}$ patients diagnose as non-muscle-invasive $\mathrm{BCa}$ (NMIBC), while $25 \%$ diagnose as muscle-invasive $\mathrm{BCa}(\mathrm{MIBC}){ }^{2}$ The 5 -year recurrence and progression rates in patients with NMIBC range from $31 \%$ to $78 \%$ and from $1 \%$ to $45 \%$, respectively. ${ }^{3}$ At present, treatment and prognosis for MIBC are mainly based on tumor and nodal stage. Radical cystectomy (RC) is the standard treatment for localized MIBC and high-risk NMIBC. However, over the past three decades, the long-term survival rate of $\mathrm{BCa}$ has not improved significantly, because of the lack of more effective treatments and accurate prognostic risk assessment markers. Patients treated with RC for MIBC have a $5-15 \%$ probability of pelvic recurrence, a $50 \%$ probability of distant recurrence, ${ }^{4,5}$ and the five-year overall survival rate is approximately $50 \% .^{6}$ Therefore, the identification of new prognostic markers and therapeutic targets for $\mathrm{BCa}$ is urgently required. 
GAS6 was originally isolated as growth arrest specific gene 6 and belongs to the vitamin K-dependent (VKD) family. Through binding to its receptors Tyro3, Axl, and Mer (TAM), GAS6 regulates several biological processes in cells, including proliferation, migration, differentiation, and adhesion. ${ }^{7}$ Recent studies have found that the activation of the GAS6/TAM signaling pathway plays an important role in the generation and progression of a wide variety of human cancers. ${ }^{8-12}$ In addition, upregulation of GAS6 is often significantly associated with worse clinical outcomes, including upper tract urothelial carcinoma, oral squamous cell carcinoma, lung adenocarcinoma, and renal cell carcinoma. ${ }^{13-16}$ However, the role of GAS6 in BCa remains largely unknown.

In the present study, by bioinformatics analysis and IHC staining of tissue microarray, we found that GAS6 is highly expressed in bladder cancer and is significantly associated with tumor grade, T stage, and worse prognosis. We found that GAS6 depletion inhibited proliferation and invasion of $\mathrm{BCa}$ cells. In addition, Bioinformatics analysis revealed that GAS6 may be involved in the regulation of the PI3K-AKT signaling pathway by binding to the receptor TAM and has a significant positive correlation with PI3K family gene expression. Furthermore, the functions and mechanisms of GAS6 in the development of BCa were explored.

\section{Materials and Methods}

\section{Patients and Specimens}

In the present study, all patients signed written informed consent forms, and the protocol was approved by the Ethics Committee of Shanghai Tenth People's Hospital of Tongji University (number: SHSY-IEC-4.1/19-120/01). In total, five pairs of $\mathrm{BCa}$ and corresponding normal tissues were obtained from the biological sample library, 60 cases of paraffin-embedded tissues of bladder cancer were obtained from the Department of Urology. All surgical specimens have a confirmed diagnosis of urothelial carcinoma of the bladder. Clinicopathological features and survival of 60 patients with RC between January 2009 and December 2015 were collected from the database of the Department of Urology of Shanghai Tenth People's Hospital of Tongji University.

\section{Quantitative RT-PCR Analysis}

Total RNA was isolated from bladder cell lines using Trizol (Invitrogen Life Technologies, CA, USA) and converted into cDNA using the PrimeScript RT Reagent Kit
(Takara Biotechnology, Dalian, China) according to manufacturer instructions. Real-time quantitative PCR (qPCR) was carried out using KAPA SYBR FAST qPCR kit on the ABI Prism 7900 fast Sequence Detection System (Applied Biosystem, Foster City, CA, USA). For qPCR, $10 \mathrm{ng}$ cDNA were amplified in a $20 \mathrm{ul}$ reaction according to manufacturer instructions. The $2^{-\Delta \Delta C t}$ method was used to assess relative quantities for the relative expression of GAS6. The primers were:

5'-ACTGTATCATCTGAACCTGACC-3' (forward) and

'-CATCCAGACGAGGGTTTATAGG-3' (reverse) for GAS6,

5'-CCTGGCACCCAGCACAAT-3' (forward) and 5'-GGGCCGGACTCGTCATAC-3' (reverse) for $\beta$-actin.

Each experiment was conducted in triplicate.

\section{Tumor Microarray and Immunohistochemistry (IHC)}

Tissue microarrays were made using paraffin tissues from 60 patients with RC. Twenty pairs of fresh human bladder cancer and adjacent normal tissues were fixed in $4 \%$ paraformaldehyde, dehydrated in ethanol solution, and then embedded in paraffin. IHC was performed as described previously. ${ }^{17}$ Anti-GAS6 antibody for IHC was purchased from Cell Signaling Technology (CST, Boston, MA).

\section{Cell Culture}

Human BCa cell lines T24, UMUC3, 5637, and J82, and the immortalized human normal bladder epithelial cell line SV-HUC-1 were purchased from the Type Culture Collection of the Chinese Academy of Sciences (Shanghai, China). T24, UMUC3, and 5637 cells were maintained in RPMI-1640 medium (Gibco; Thermo Fisher Scientific, Inc., Waltham, MA, USA), while J82 cells were maintained in Dulbecco's modified Eagle's medium (Gibco; Thermo Fisher Scientific, Inc.). SVHUC-1 cells were maintained in F12K medium (SigmaAldrich; Merck KGaA, Darmstadt, Germany). All cell culture media were supplemented with $10 \%$ fetal bovine serum (FBS; Gibco; Thermo Fisher Scientific, Inc.) and 1\% penicillin/streptomycin (HyClone; GE Healthcare Life Sciences, Logan, UT, USA). All cell lines were maintained at $37^{\circ} \mathrm{C}$ in a humidified incubator containing $5 \% \mathrm{CO} 2$.

\section{Transient Transfection}

Small interfering RNAs (siRNA) that specifically knock down human GAS6 (si-GAS6) and negative control 
oligonucleotides (si-NC) were purchased from GenePharma (Shanghai, China). siRNA was transiently transfected into cells using lipofectamine 3000 (Invitrogen; Thermo Fisher Scientific, Inc., Waltham, MA). The si-GAS6 sequences were as follows:

SiRNA\#1 5'-GCCUCCAGAUCUGCCACAATT-3', siRNA\#2 5'-CCUGACCGUGGGAGGUAUUTT-3', siRNA\#3 5'-GCAUACGGCCUUGGCCCUATT-3'. The negative control siRNA sequences were: 5'-UUCUCCGAACGUGUCACGUTT-3'.

Total proteins were extracted at 48 hours after transfection.

\section{Cell Proliferation}

The CCK-8 assay was performed to evaluate cell proliferation according to manufacturer instructions (Yeasen, Shanghai, China). Twenty-four hours after cell transfection, 1000 cells were seeded into each 96-well plate with $100 \mathrm{~mL}$ culture medium (10\% FBS). Then, $10 \mu \mathrm{L} \mathrm{CCK}-8$ solution was added to each plate at 1, 2, 3, 4 or 5 days and cultured for $2 \mathrm{~h}$ at $37^{\circ} \mathrm{C}$. The absorbance at $450 \mathrm{~nm}$ was measured with a microplate spectrophotometer (BioTek, Winooski, VT, USA).

\section{Colony Formation Assays}

The cell proliferation was furthermore evaluated by colony formation assays. At $24 \mathrm{~h}$ after cell transfection, 500 cells were seeded in six-well plates. After 2 weeks, the colonies were fixed with $95 \%$ ethanol, stained with $0.1 \%$ crystal violet. Colony size and number were used to assess proliferative capacity.

\section{Cell Cycle Analysis}

At $48 \mathrm{~h}$ after cell transfection, cells were harvested, sequentially washed twice with cold PBS, and then fixed in $70 \%$ ethanol at $4^{\circ} \mathrm{C}$ overnight. Then, cells were washed with cold PBS, centrifuged and stained with propidium iodide (PI) containing RNase in the dark at $37^{\circ} \mathrm{C}$ for 15 min. Flow cytometry was used to perform cell cycle analysis using BD FACS Calibur. Each experiment was conducted in triplicate.

\section{Cell Migration and Invasion Assays}

Transwell chambers were purchased from Corning (Lowell, MA, USA). For the cell migration assay, after cell transfection at $24 \mathrm{~h}, 5 \times 10^{4}$ cells were added into the upper chamber of the Transwell chamber in $200 \mu \mathrm{L}$ medium without FCS, with $500 \mu \mathrm{L}$ culture medium containing
$10 \% \mathrm{FCS}$ in the lower chamber. Cells were maintained for $24 \mathrm{~h}$ at $37^{\circ} \mathrm{C}$. The number of invaded cells was counted as previously described. ${ }^{17}$

For the cell invasion assay, the Transwell filters were precoated using Matrigel according to the manufacturer's recommendations (BD Biosciences, Franklin Lakes, NJ, USA). The subsequent experiments were the same as the migration assay. Each experiment was conducted in triplicate.

\section{Western Blot}

The total cell proteins were extracted with RIPA buffer supplemented with protease inhibitors. Total proteins (30 $\mu \mathrm{g})$ were separated by SDS/PAGE and blotted onto a nitrocellulose (NC) membrane. Membranes were incubated with primary antibody against GAS6 (\#67202, CST, Boston, MA), cyclinD1 (ab40754, Abcam, Cambridge, MA, USA.), cyclinE1 (ab33911, Abcam), p21 (\#2947, CST), p27 (\#3686, CST), total AKT (\#2920, CST), PI3K (\#4255, CST), and phospho-AKT (\#4060, CST). GAPDH (ab181602, Abcam) overnight at $4{ }^{\circ} \mathrm{C}$. The protein band was identified using an Odyssey scanner (Li-COR Biosciences, Lincoln, NE, USA.). The expression of GAPDH was used as an internal control.

\section{Xenografts in Mice}

This study was performed following the institutional and national guidelines and regulations of the Animal Protection and Use Committee and approved by the Ethics Committee of Shanghai Tenth People's Hospital of Tongji University (SHDSYY-2019-3028). In brief, 12 4-week-old male nude BALB/c mice were subcutaneously injected with $2 \times 10^{6}$ T24 cells. Tumor size was measured once every 3 days using a Vernier caliper and tumor xenograft volume calculated as follows: length $\times$ width $^{2}$ $\times 0.5$. After 30 days, mice were sacrificed, and all tumor xenografts were collected.

\section{Statistical Analysis}

Data were analyzed using SPSS 24.0 software (Chicago, IL, USA) and Prism 7 software (GraphPad Software, Inc., La Jolla, CA). Data are shown as mean \pm standard deviation (SD). The Student's $t$-test was performed to determine the differences between the two groups. The association between GAS6 expression and clinicopathological features was evaluated using chi-square test or Fisher's exact test. $\mathrm{P}<0.05$ were considered statistical significance. 


\section{Results}

High Expression of GAS6 Is Associated with Clinical Parameters and Worse Overall Survival

In this study, we performed bioinformatics analysis of TCGA data and identified GAS6 as a potential prognostic biomarker in survival for BCa. To confirm this finding, we detected GAS6 protein expression in $\mathrm{BCa}$ samples and cell lines by IHC and Western blot. IHC staining showed that GAS6 expression was noticeably higher in $\mathrm{BCa}$ than in the paired non-neo-plastic BCa samples (14 (70\%) vs.6 (30\%), $\mathrm{P}<0.05)$ (Figure 1A). Similarly, we found that GAS6 was overexpressed in BCa cell lines compared with SV-HUC-1 normal cells by the Western blot (Figure 1B). IHC staining showed that GAS6 expression was higher in high-grade $\mathrm{BCa}$ (Figure 1C). Additionally, 50 of the 60 cases in the tissue microarray were available, and IHC staining showed the correlation between GAS6 overexpression and tumor $\mathrm{T}$ stage and $\mathrm{N}$ stage (Figure 1D; Table 1, $\mathrm{P}<0.05$ ). These findings are consistent with the results of the Oncomine open cancer microarray database (https://www.oncomine.org/) (Figure $1 \mathrm{E}$ and $\mathrm{F}$, all $\mathrm{P}<0.05$ ). Furthermore, Kaplan-Meier survival analysis showed that high expression of GAS6 was significantly associated with poor overall survival (OS) (Log-rank test: $\mathrm{P}=0.009$; Figure $1 \mathrm{G}$ ). The finding is consistent with the result of Kaplan Meier Plotter database (http:// kmplot.com/analysis/) (Figure 1H, $\mathrm{P}<0.05$ ).

\section{Knockdown GAS6 Expression Inhibits Proliferation, Migration, and Invasion of BCa Cells}

To determine the function of GAS6 on $\mathrm{BCa}$, GAS6 siRNAs \#1-3 were designed and transfected into the BCa cell lines, UMUC-3 and T24. Western blot confirmed that the cells with GAS6 siRNA \#1 showed the most effective GAS6 knockdown among three siRNAs (Figure $2 \mathrm{~A}$ and $\mathrm{B}$, all $\mathrm{P}<0.05$ ). Furthermore, specific GAS6 siRNA \#1 was transfected into UMUC-3 and T24 (Figure $2 \mathrm{C}$, all $\mathrm{P}<0.05$ ), to examine cell proliferation and invasion by CCK- 8 and colony formation assays. The CCK-8 assay showed that silencing GAS6 significantly leads to reduced proliferation of UMUC-3 and T24 cells, compare with si-NC group (Figure 2D, $\mathrm{P}<0.05$ ). Consistently, GAS6 knockdown significantly decreased the colony formation rate of UMUC-3 and T24 cells (Figure $2 \mathrm{E}, \mathrm{P}<0.05$ ). To evaluate the influences of GAS6 on migration and invasion of $\mathrm{BCa}$ cell, specific GAS6 siRNA \#1 was transfected into UMUC-3 and T24, which were used for the Transwell migration and invasion assays. The number of migrating and invasive UMUC-3 and T24 cells significantly decreased when GAS6 was knocked down (Figure $2 \mathrm{~F}$ and $\mathrm{G}$ ). These findings suggest that GAS6 plays a critical role in proliferation, migration, and invasion of $\mathrm{BCa}$ cells.

\section{GAS6 Knockdown Induces BCa Cell Cycle Arrest by Decreasing Cell Cycle-Related Gene Expression}

To further examine the effect of GAS6 on cell proliferation, we performed flow cytometry to analyze changes in the cell cycle distribution of the UMUC-3 and T24 cells after GAS6 silencing. The results show that GAS6 knockdown led to increases in the percentage of cells in the G1 phase and a corresponding decrease in the $\mathrm{S}$ phase, compared with the control group (Figure $3 \mathrm{~A}$, all $\mathrm{P}<0.05$ ). These data suggest that knockdown of GAS6 expression resulted in $\mathrm{BCa}$ cell cycle arrest at G1 phase. To investigate the underlying mechanism of cell cycle arrest, expression of G1 phase cell cycle-related genes was evaluated by Western blot. Our data indicate that cyclin D1 and cyclin E1 expression was increased while the expression of p27 and p21 was decreased in $\mathrm{BCa}$ cells transfected with GAS6 siRNA (Figure 3B and $C$, all $\mathrm{P}<0.05$ ). Collectively, these findings suggest that the GAS6 may promote proliferation of BCa cells by inducing cell cycle-related gene expression.

\section{GAS6 Knockdown Inhibits BCa Growth in vivo}

To investigate the effect of GAS6 on BCa growth in vivo, we first established UMUC-3 and T24 cell lines with stable expression of GAS6 knockdown (Figure 4A and B), and we performed a xenograft tumor model experiment by subcutaneously injecting UMUC-3 shGAS6, UMUC-3 shNC, T24 shGAS6 and T24 shNC into nude mice. Tumor size was monitored over time with a Vernier caliper. We found tumor size and volume were significantly reduced in the GAS6 knockdown group compared with the controls on day 18 , 24 , and 30 (all $\mathrm{P}<0.05$ ) (Figure $4 \mathrm{C}-\mathrm{F}$ ). Similarly, the tumor weight of the GAS6 knockdown group was significantly lighter than that of the shNC group when the tumors were harvested and weighed on day 30 (Figure $4 \mathrm{G}$ and $\mathrm{H} \mathrm{P}<0.05$ ). Together, these results support the hypothesis that GAS6 overexpression promotes proliferation in $\mathrm{BCa}$. 

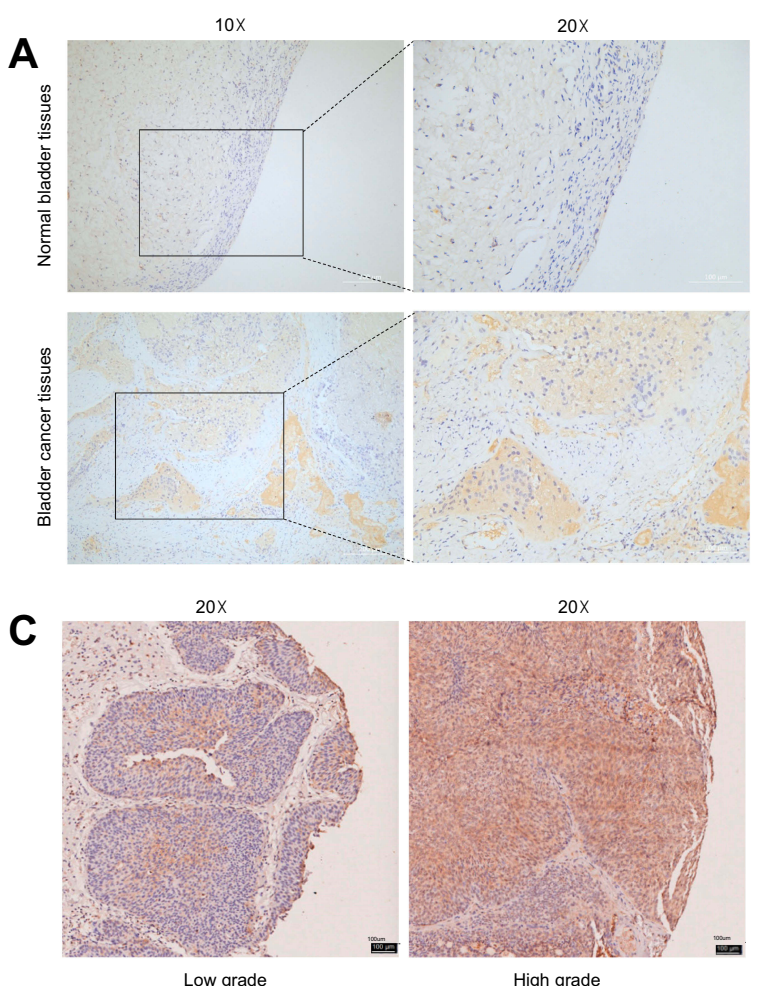

$20 x$

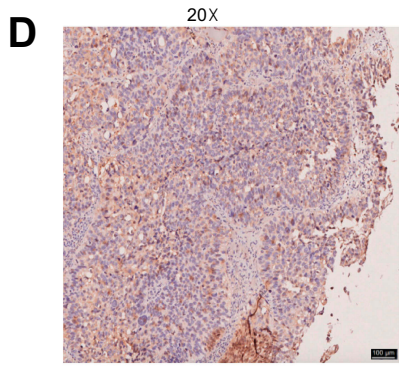

Non-muscle-invasive Bladder Cancer

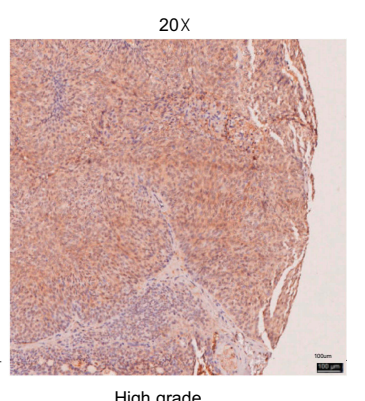

High grade

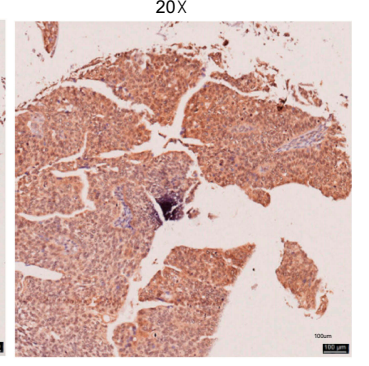

Muscle-invasive Bladder Cancer
G

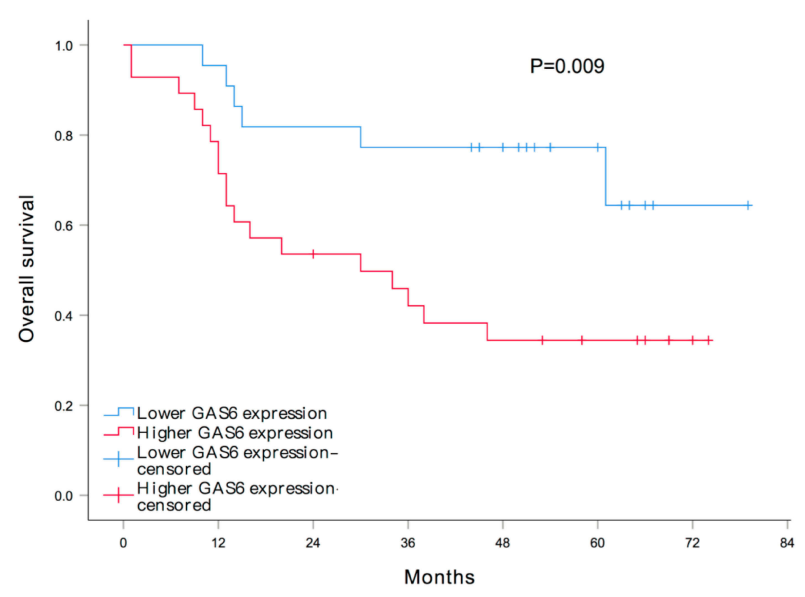

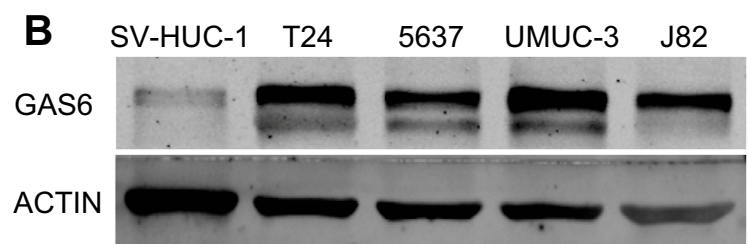

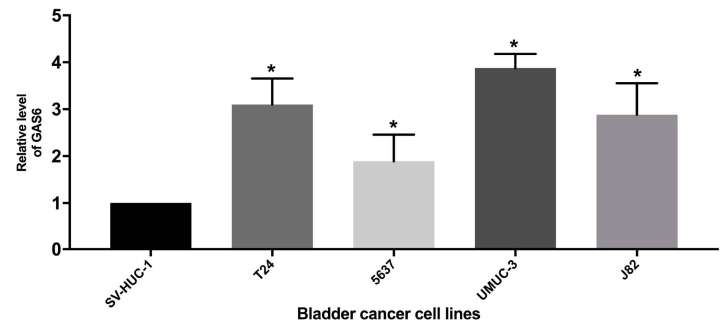

E

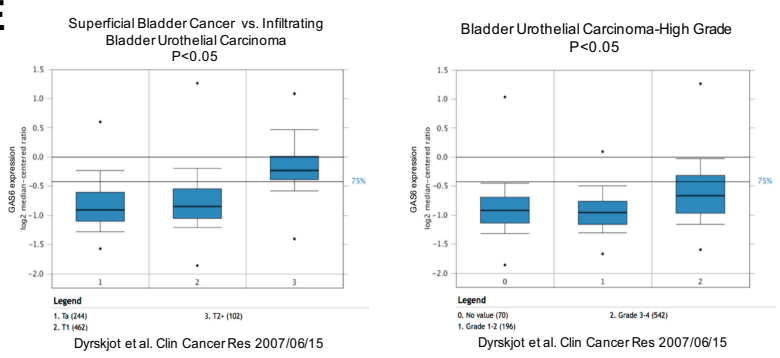

F
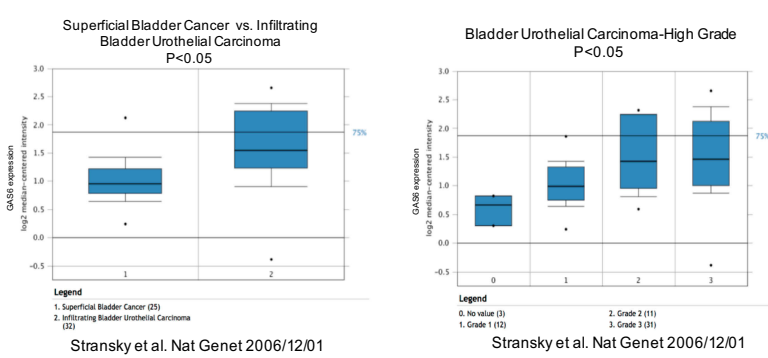

H

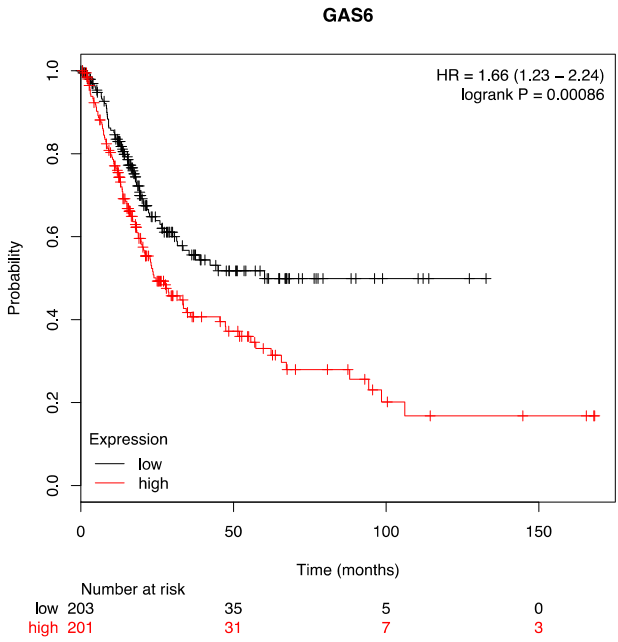

Figure I High expression of GAS6 is associated with clinical parameters and worse overall survival. (A and B) The expression of GAS6 in BCa samples and BCa cell lines by the IHC, qRT-PCR, and Western blot (scale bar $=200 \mu \mathrm{m}$ for $10 \times$ and $100 \mu \mathrm{m}$ for $20 \times$ ). (C and D) IHC staining shows the correlation between GAS6 expression and tumor T stage and histologic grade (scale bar $=100 \mu \mathrm{m}$ for $20 \times$ ). ( $(\mathbf{E}$ and $\mathbf{F}$ ) The correlation between GAS6 expression and tumor T stage and histologic grade in BCa derived from Oncomine database (https://www.oncomine.org/). (G) Kaplan-Meier survival analysis shows the association between the expression of GAS6 and OS, the Log-rank test was used to assess the significance. (H) Prognosis of BCa patients with low or high expression of GAS6 derived from Kaplan Meier Plotter database (http://kmplot.com/analysis/). Data are shown as mean \pm SD. *Statistically significant $(P<0.05)$. 
Table I Correlation Between GAS6 Expression and Clinicopathologic Parameters in Patients with $\mathrm{BCa}$

\begin{tabular}{|c|c|c|c|c|}
\hline Parameters & $\begin{array}{l}\text { No. of } \\
\text { Patients }\end{array}$ & $\begin{array}{l}\text { Low } \\
\text { Expression } \\
\text { of GAS6 }\end{array}$ & $\begin{array}{l}\text { High } \\
\text { Expression } \\
\text { GAS6 }\end{array}$ & $P$ value \\
\hline $\begin{array}{c}\text { Gender } \\
\text { Male } \\
\text { Female }\end{array}$ & $\begin{array}{l}44 \\
6\end{array}$ & $\begin{array}{l}19 \\
3\end{array}$ & $\begin{array}{l}25 \\
3\end{array}$ & 1.000 \\
\hline $\begin{array}{l}\text { Age (years) } \\
\quad \leq 65 \\
>65\end{array}$ & $\begin{array}{l}21 \\
29\end{array}$ & $\begin{array}{l}13 \\
9\end{array}$ & $\begin{array}{l}8 \\
20\end{array}$ & $0.030^{*}$ \\
\hline $\begin{array}{l}\text { BMI } \\
\quad \leq 24 \\
>24\end{array}$ & $\begin{array}{l}28 \\
22\end{array}$ & $\begin{array}{l}14 \\
8\end{array}$ & $\begin{array}{l}14 \\
14\end{array}$ & 0.335 \\
\hline $\begin{array}{l}\text { Hypertension } \\
\text { No } \\
\text { Yes }\end{array}$ & $\begin{array}{l}31 \\
19\end{array}$ & $\begin{array}{l}15 \\
7\end{array}$ & $\begin{array}{l}16 \\
12\end{array}$ & 0.425 \\
\hline $\begin{array}{c}\text { Diabetes } \\
\text { No } \\
\text { Yes }\end{array}$ & $\begin{array}{l}41 \\
9\end{array}$ & $\begin{array}{l}19 \\
3\end{array}$ & $\begin{array}{l}22 \\
6\end{array}$ & 0.733 \\
\hline $\begin{array}{l}\text { Histologic } \\
\text { grade } \\
\text { Low } \\
\text { High }\end{array}$ & $\begin{array}{l}4 \\
46\end{array}$ & $\begin{array}{l}1 \\
21\end{array}$ & $\begin{array}{l}3 \\
25\end{array}$ & 0.785 \\
\hline $\begin{array}{l}\text { T stage } \\
\leq \mathrm{TI} \\
\text { T2-T4 }\end{array}$ & $\begin{array}{l}22 \\
28\end{array}$ & $\begin{array}{l}14 \\
8\end{array}$ & $\begin{array}{l}8 \\
20\end{array}$ & $0.013^{*}$ \\
\hline $\begin{array}{l}\mathrm{N} \text { stage } \\
\text { Negative } \\
\text { Positive }\end{array}$ & $\begin{array}{l}39 \\
11\end{array}$ & $\begin{array}{l}21 \\
1\end{array}$ & $\begin{array}{l}18 \\
10\end{array}$ & $0.008 *$ \\
\hline $\begin{array}{c}\text { M stage } \\
\text { Mo } \\
\text { MI }\end{array}$ & $\begin{array}{l}45 \\
5\end{array}$ & $\begin{array}{l}20 \\
2\end{array}$ & $\begin{array}{l}25 \\
3\end{array}$ & 1.000 \\
\hline $\begin{array}{l}\text { Tumor size } \\
\begin{array}{l}\text { (cm) } \\
\leq 3.5 \\
>3.5\end{array}\end{array}$ & $\begin{array}{l}27 \\
23\end{array}$ & $\begin{array}{l}10 \\
12\end{array}$ & $\begin{array}{l}17 \\
11\end{array}$ & 0.283 \\
\hline
\end{tabular}

Note: *Statistically significant $(P<0.05)$.

\section{GAS6 Silencing Inhibits Proliferation and Invasion of $\mathrm{BCa}$ Cells by Inactivating the PI3K/AKT Signaling}

\section{Pathway}

To further explore the intra-cellular downstream signals that are involved in the GAS6-mediated increase in $\mathrm{BCa}$ cell proliferation and invasion, we performed a KEGG signal network analysis and found PI3K/AKT signaling is a potential downstream pathway for GAS6. Next, we examined the correlation between GAS6 and the PI3K gene family in the TCGA database using the online tool GEPIA. The results revealed that expression of the GAS6 gene is correlated with PIK3CA, PIK3CD, and PIK3CG (all $\mathrm{P}<0.05$, Figure 5A-D). Furthermore, we examined the role of GAS6 in PI3K/AKT signaling. Western blot analysis indicated that knockdown of GAS6 expression significantly reduced PI3K and p-AKT expression but had no effect on total AKT (Figure 5E and $\mathrm{F}$, all $\mathrm{P}<0.05$ ). Furthermore, we treated shGAS6-silencing UMUC-3 and T24 cells with the AKT activator SC79. Through performing CCK8 assay and Transwell invasion assay, we found that SC79 partially restore the effect of GAS6 silencing on cell proliferation and invasion (Figure $5 \mathrm{G}$ and $\mathrm{H}$, all $\mathrm{P}<0.05$ ). Together, these data demonstrate that GAS6 silencing might inhibit $\mathrm{BCa}$ progression via inactivating PI3K/AKT signaling.

\section{Discussion}

GAS6, a member of the vitamin K-dependent (VKD) family, is a protein of 678 amino acids. GAS6 activates downstream signaling pathways by its sex hormonebinding globulin (SHBG) domain interacting with Tyro3, Axl, and Mer (TAM) receptors. GAS6 has the highest affinity with AXL, followed by Tyro3, then Mer. ${ }^{18}$ Numerous studies have found that GAS6/TAM plays a key role in cancer cells, tumor microenvironment, and metastasis. ${ }^{9,19-21}$ Bioinformatics analysis showed the involvement of GAS6 in the progression and survival of $\mathrm{BCa}$. Until now, there has been no report about the specific mechanisms of GAS6 in the development of BCa.

In this study, we found that GAS6 was overexpressed in BCa cells. GAS6 overexpression was associated with poor OS and was a potential prognostic factor for patients with BCa. GAS6 knockdown reduced the expression level of PI3K/AKT-related genes and led to decreased proliferation and invasion of $\mathrm{BCa}$ cells. Therefore, we demonstrated that GAS6 plays an important role in the development of BCa by the PI3K-AKT signaling.

Previous studies have demonstrated that GAS6 is upregulated in several cancer cells, including glioma, schwannoma, melanoma, and pancreatic ductal adenocarcinoma cell lines. ${ }^{8-10,22}$ In addition, several studies have reported that GAS6 is highly expressed in human tumor tissues. $8,22,23$ Clinically, high expression of GAS6 is an independent prognostic factor for poor survival in several cancers. ${ }^{8,22}$ The underlying mechanisms of GAS6 upregulation in cancers 
A

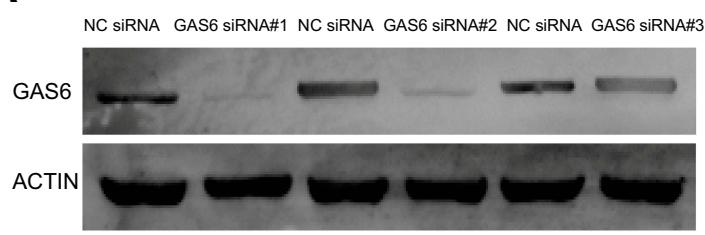

UMUC-3

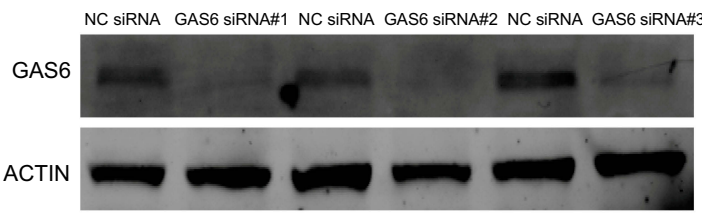

T24

C

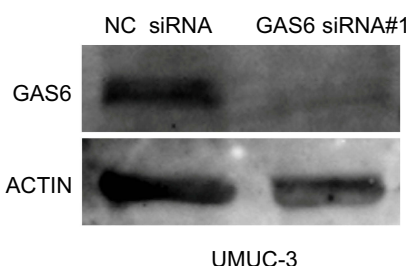

UMUC-3
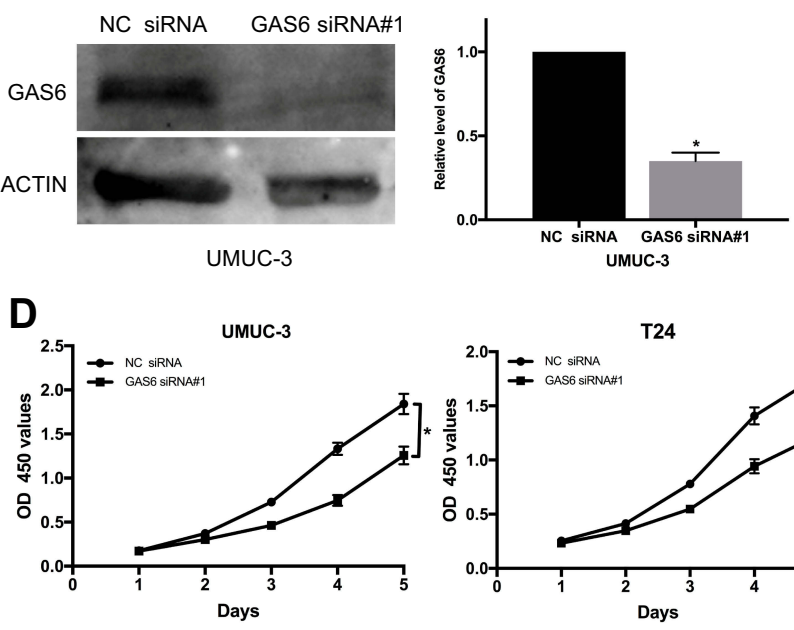

UMUC-3
B
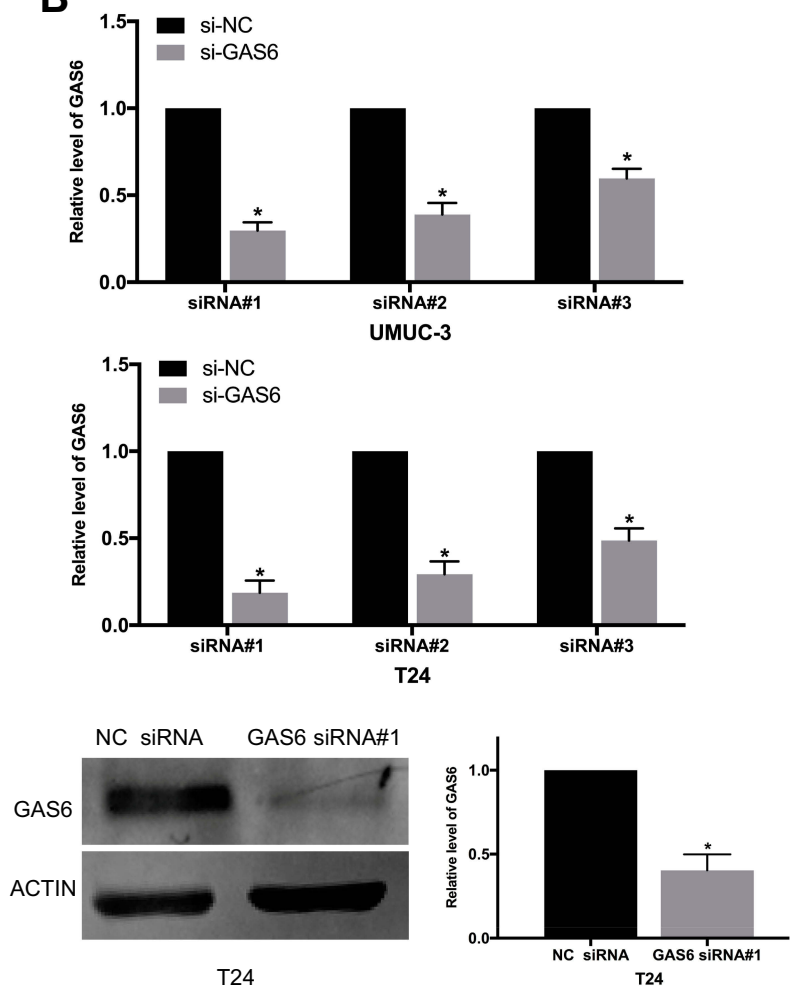

E NC SiRNA GAS6 SiRNA\#1
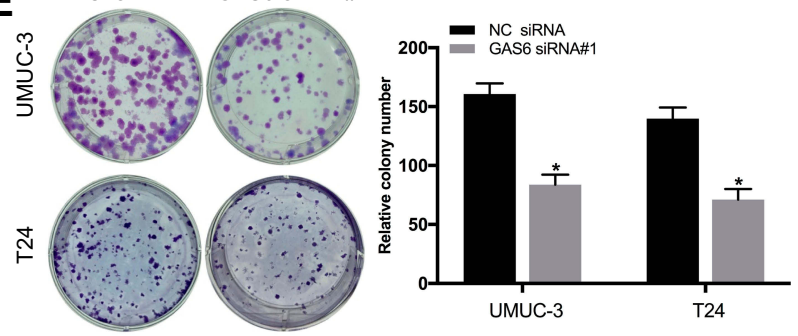

G

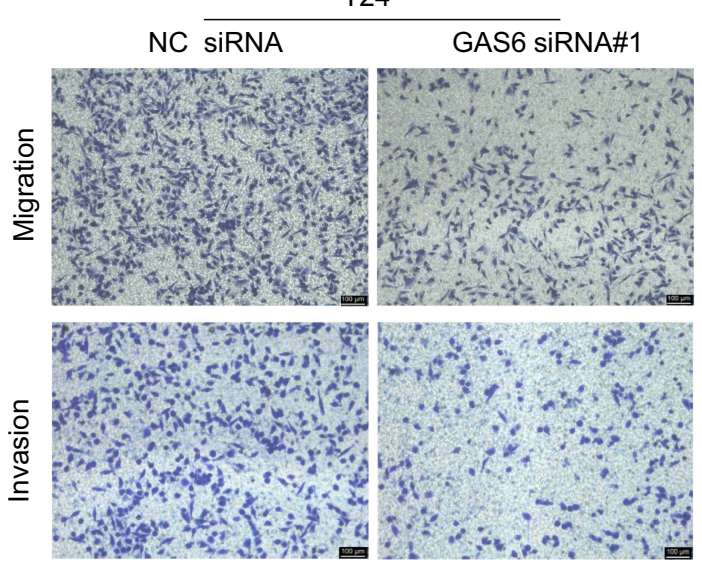

Figure 2 Knockdown of GAS6 expression inhibits proliferation, migration, and invasion of BCa cells. (A and B) GAS6 siRNA \#I is the most effective GAS6 knockdown among three siRNAs for UMUC-3 and T24 cells, as assessed by Western blot and qRT-PCR. (C) Specific GAS6 siRNA \#I was transfected into UMUC-3 and T24. (D and E) Silencing of GAS6 leads to significantly reduced proliferation of UMUC-3 and T24 cells compared to the si-NC group as assessed by CCK-8 and colony formation assay. (F and $\mathbf{G})$ Transwell assays show GAS6 knockdown inhibits the migration and invasion of UMUC-3 and T24. Data are shown as mean \pm SD. *Statistically significant $(\mathrm{P}<0.05)$. 
A
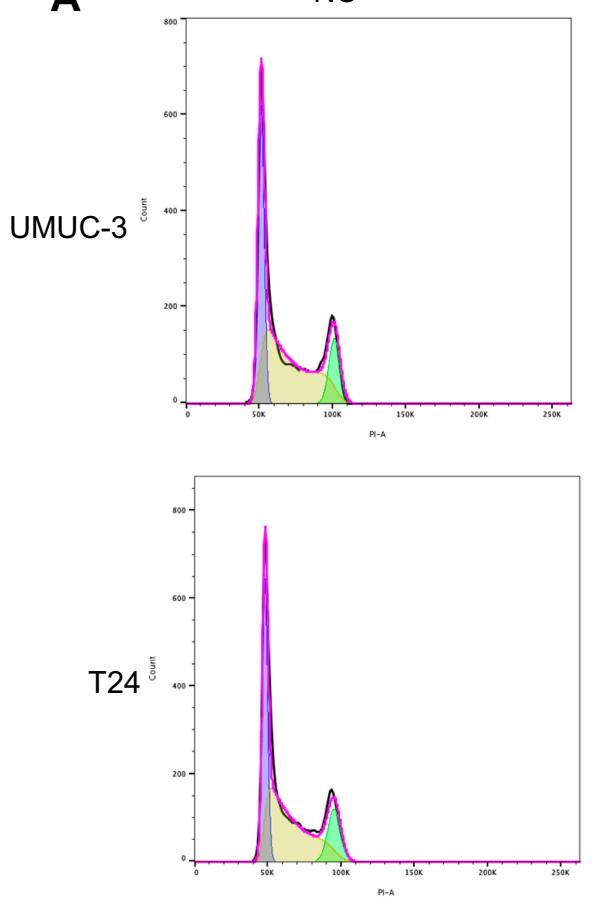

B

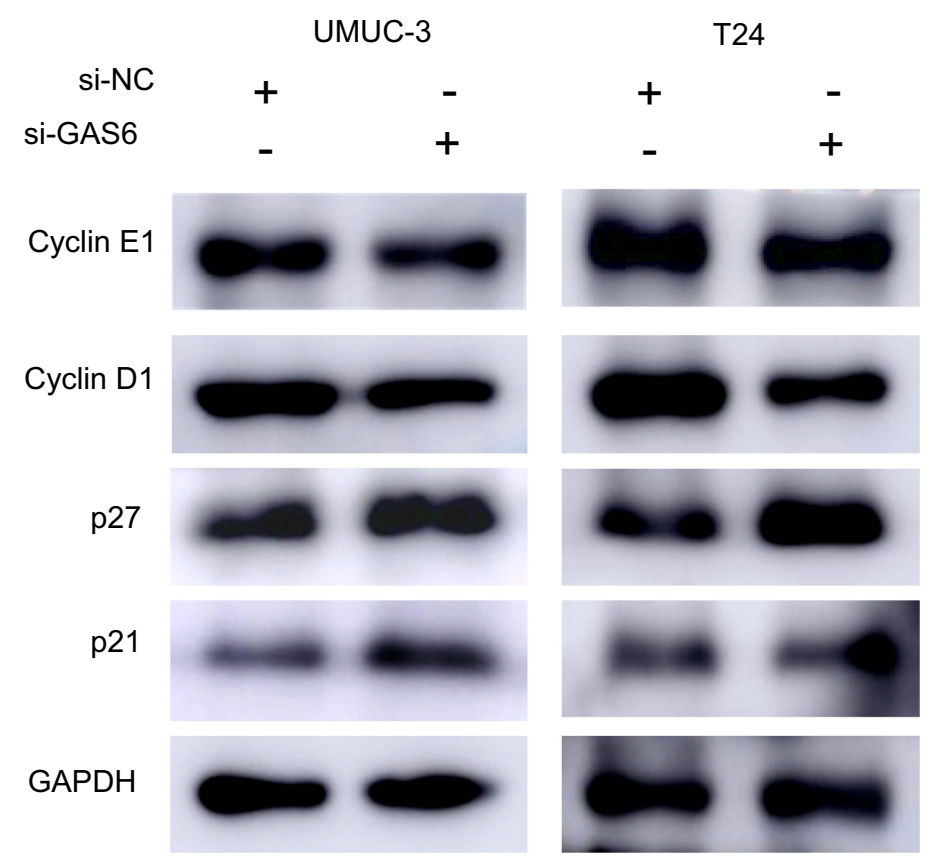

Si-GAS6
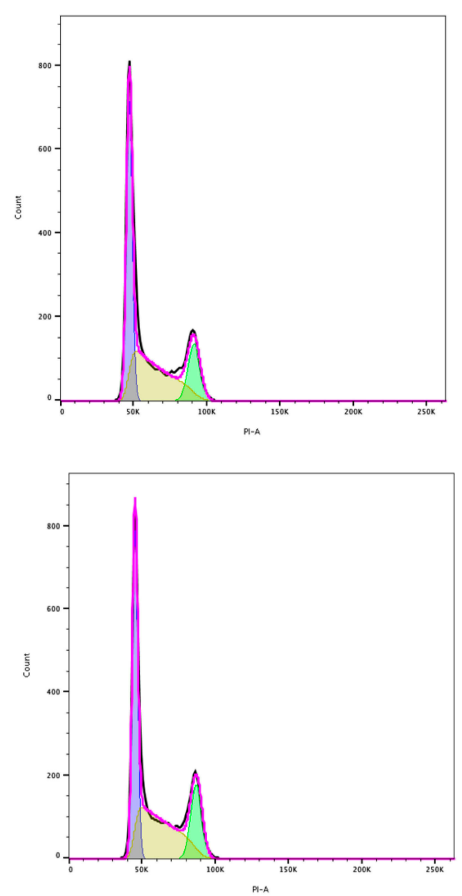
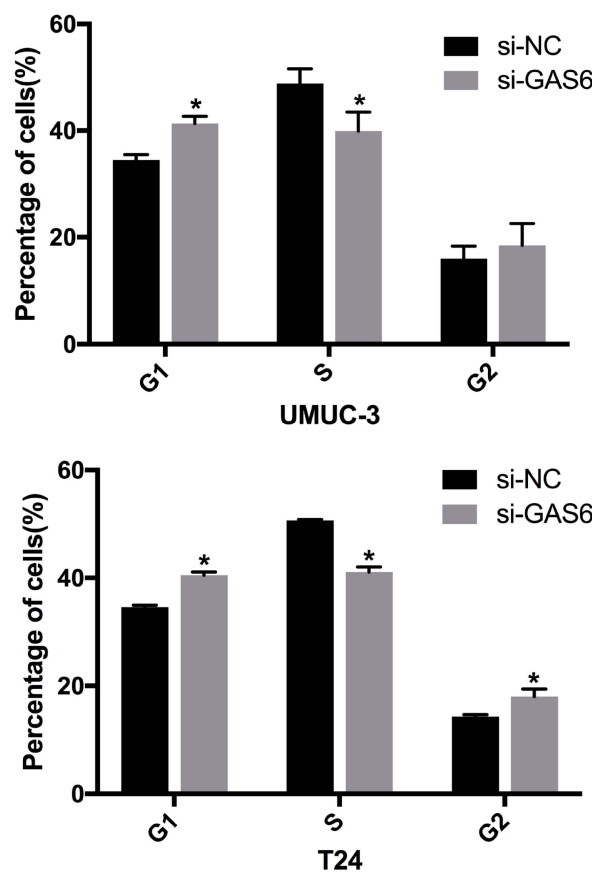

C
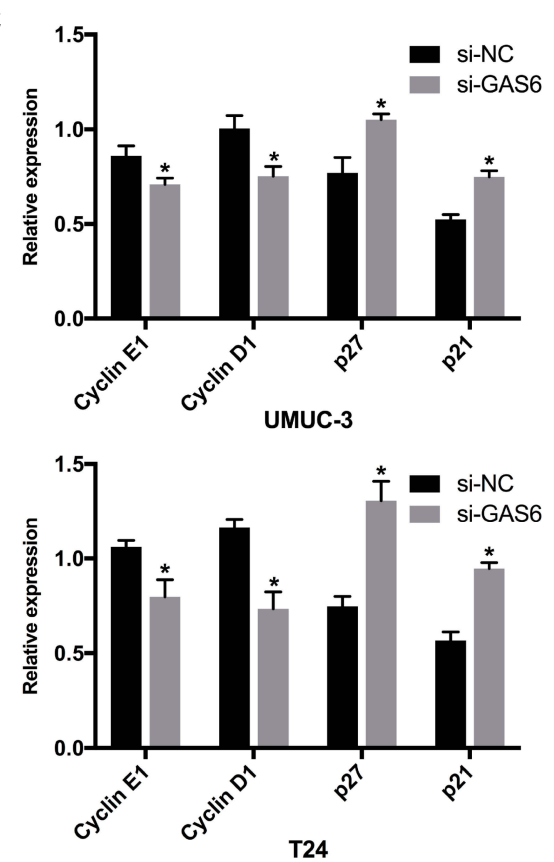

Figure 3 GAS6 knockdown induces BCa cell cycle arrest by decreasing cell cycle-related gene expression. (A) Flow cytometry analysis of changes in the cell cycle distribution of the UMUC-3 and T24 cells after GAS6 silencing. (B) Expression of GI phase cell cycle-related genes evaluated by Western blot. (C) Relative expression of each protein in UMUC-3 and T24 cells quantified using Image-J software and normalized to GAPDH. Data are shown as mean \pm SD. $*$ Statistically significant (P < 0.05$)$.

included GAS6 transcription activation of transcription factors, methylation and long non-coding RNA (lncRNA), as well as gene polymorphisms. ${ }^{24-28}$ In this study, we found GAS6 expression was elevated in four BCa cells compared with SV-HUC-1 normal cells. Tissue microarray and IHC staining showed that GAS6 expression was significantly associated with pathological stage, grade, and overall survival of BCa. These data were consistent with the Oncomine 
A

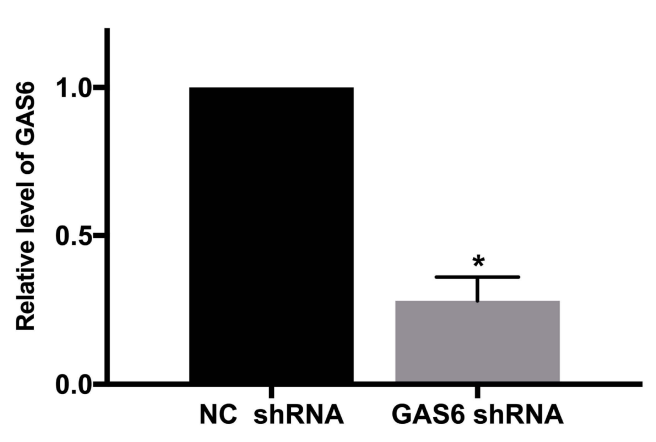

C

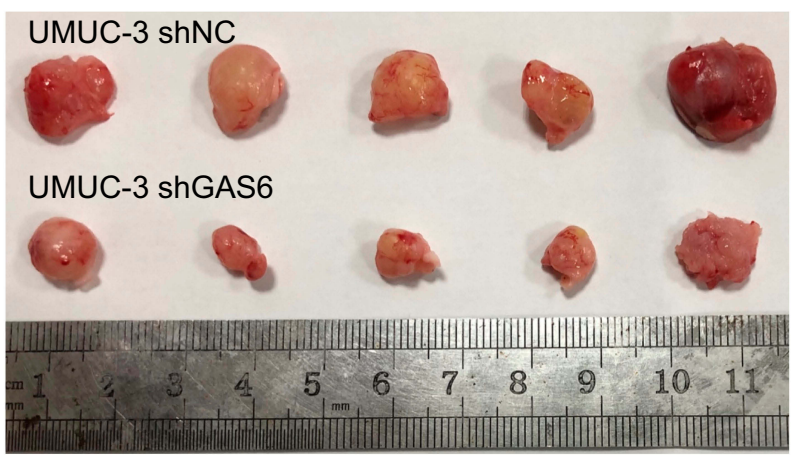

E

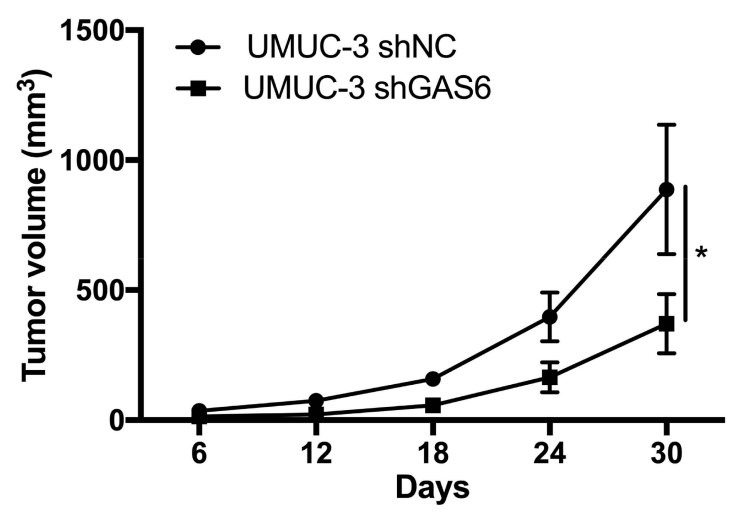

G

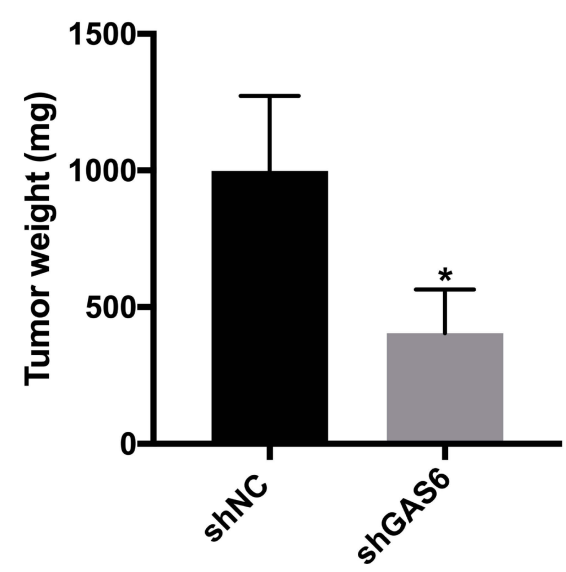

B

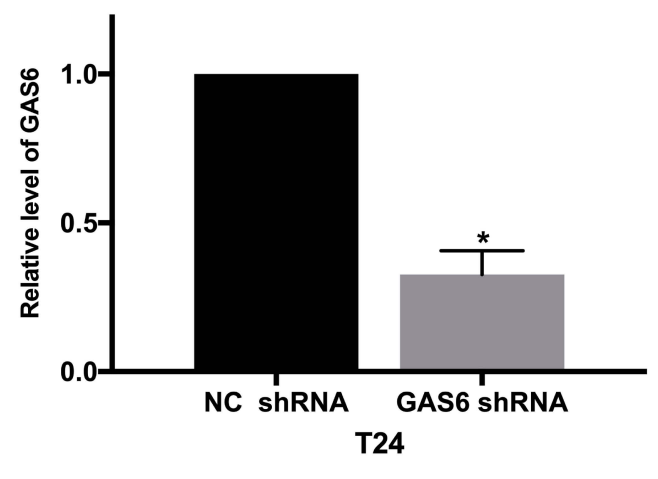

T24 shNC

T24 shGAS6

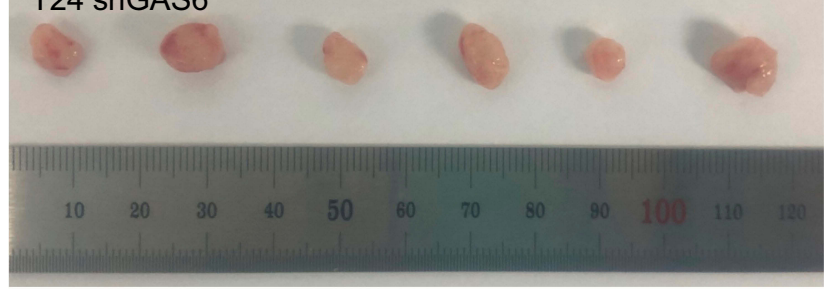

F

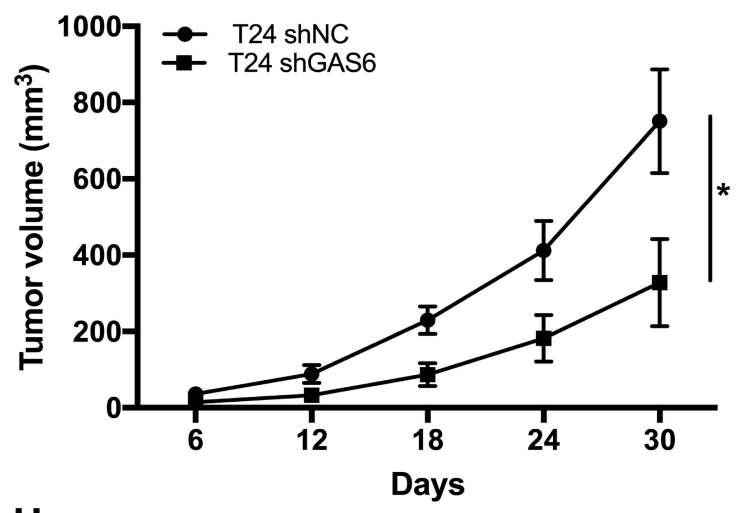

H

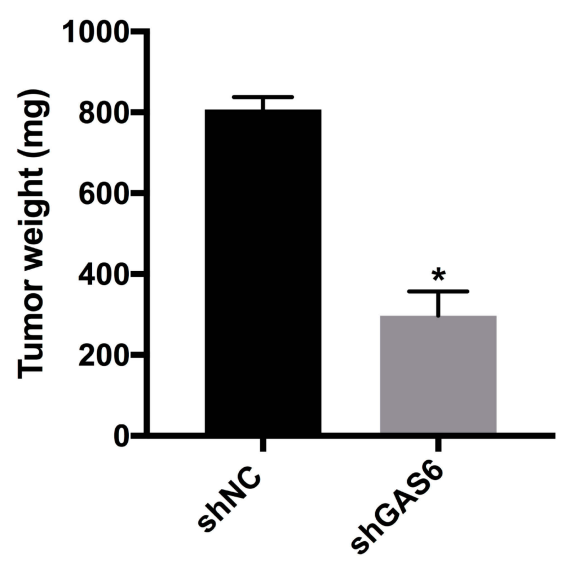

Figure 4 GAS6 knockdown inhibits bladder cancer growth in vivo. (A and B) UMUC-3 and T24 cell lines with stable expression of GAS6 knockdown were established. (C-H) Tumor size, volume, and weight compared between the GAS6 knockdown group and negative control. Data are shown as mean \pm SD. *Statistically significant $(\mathrm{P}<0.05)$. 

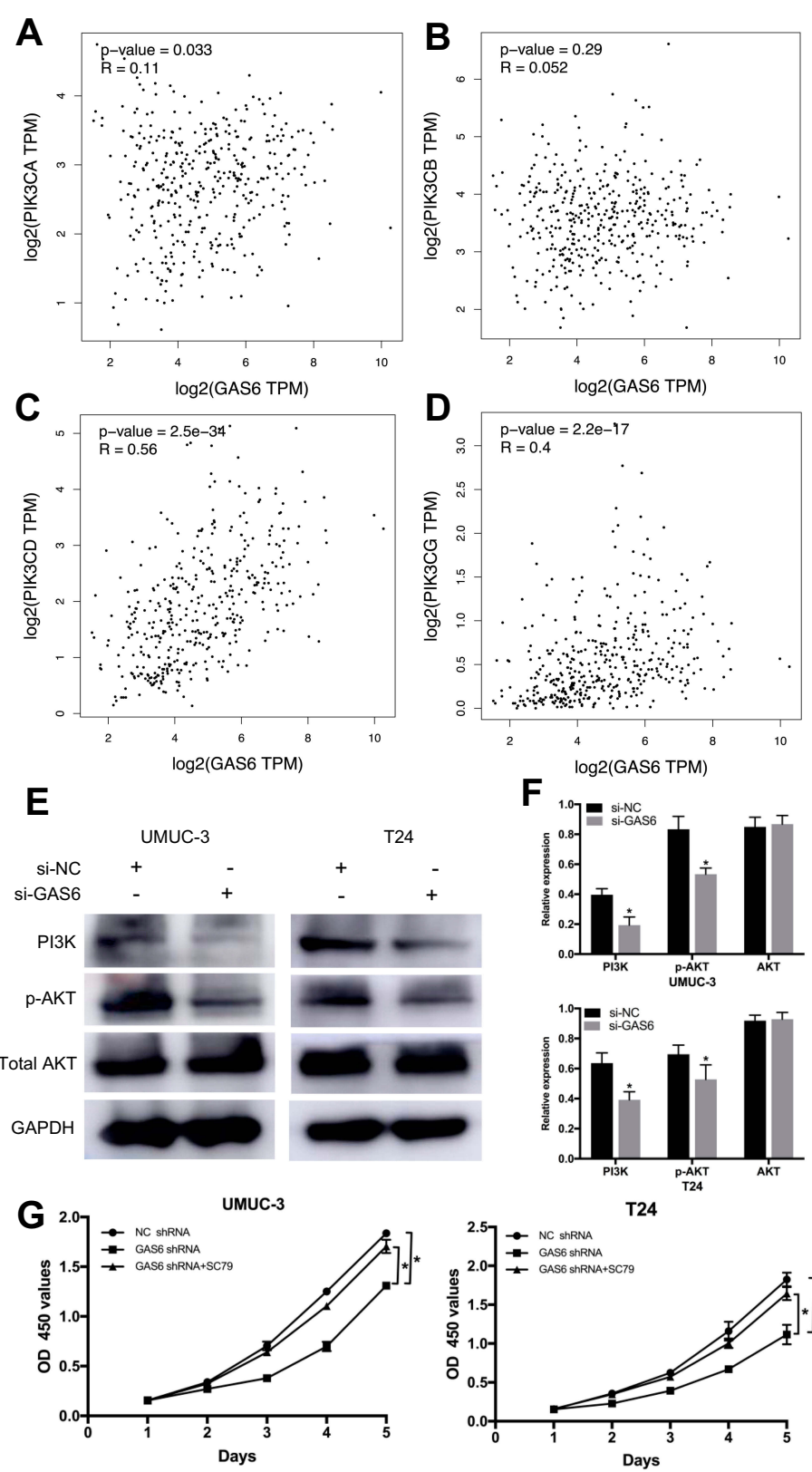

T24
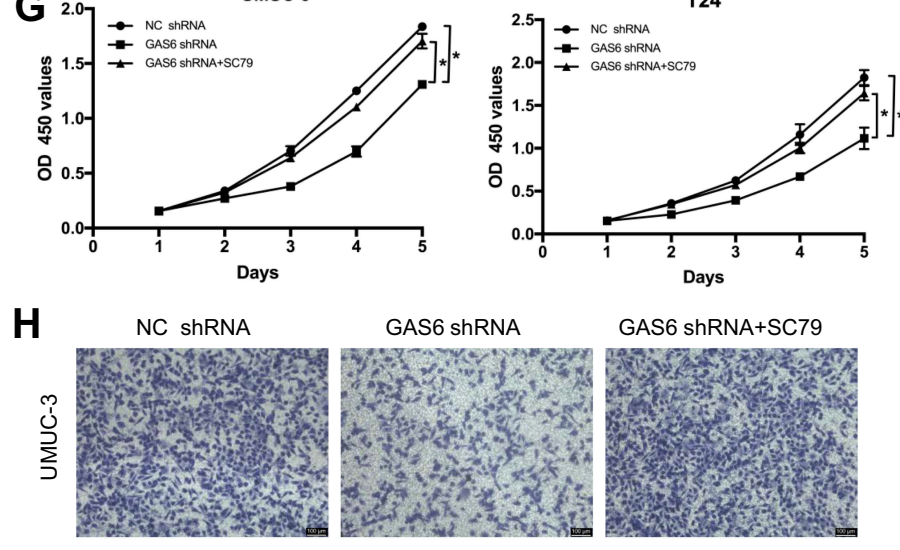

GAS6 shRNA+SC79

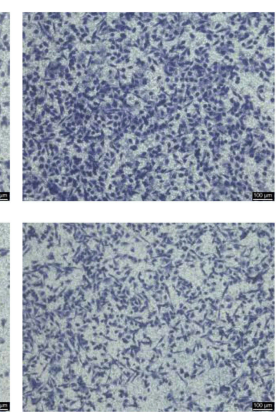

Figure 5 GAS6 knockdown inhibitors proliferation and invasion of BCa cells by inactivating PI3K/AKT signaling pathway. (A-D) Bioinformatics analysis shows that the expression of the GAS6 gene is correlated with PIK3CA, PIK3CD, and PIK3CG (all P<0.05). (E) The role of GAS6 in PI3K/AKT signaling by Western blot. (F) Relative protein expression of each protein in UMUC-3 and T24 cells was quantified using Image-J software and normalized to GAPDH. (G) SC79 treatment partially restored the effect of GAS6 silencing on cell proliferation by CCK8 assays (all $\mathrm{P}<0.05)$. $(\mathbf{H})$ Transwell assays revealed that SC79 treatment partially restored the effect of GAS6 silencing on cell invasion. Data are shown as mean $\pm \mathrm{SD}$. * Statistically significant $(\mathrm{P}<0.05)$. 
and TCGA database analysis. Together with our results, these data suggest that upregulation of GAS6 may promote the development of BCa. However, the potential mechanism of GAS6 upregulation in $\mathrm{BCa}$ has not been investigated. Interestingly, Bester et al found lncRNA GAS6-AS2 could lead to hyperactivation of the GAS6/TAM pathway to promote cellular survival and resistance to cytarabine treatment in acute myeloid leukemia. ${ }^{26}$ Besides, Rui et al have shown that IncRNA GAS6-AS2 was significantly up-regulated in $\mathrm{BCa}$ tissues and positively correlated with tumor stages and poor prognosis, and it could promote the proliferation and metastasis of bladder cancer cells. ${ }^{28}$ So, it may be inferred that lncRNA GAS6-AS2 in bladder cancer may up-regulate GAS6 and promote progression of bladder cancer.

We furthermore focused on the functional role of GAS6 in the progression of $\mathrm{BCa}$. It has been observed that GAS6 is involved in proliferation and invasion of multiple cancer cells. A recent study reported that GAS6 knockdown inhibited the growth of prostate cancer cells by reducing AKT and MAPK phosphorylation. ${ }^{12}$ Another study revealed that GAS6 promoted proliferation of schwannoma cells via induction of SRC, focal adhesion kinase (FAK), and NF-кB. ${ }^{6}$ Additionally, GAS6 involves tumor cell proliferation by activating ERK signaling pathway. ${ }^{10}$ Moreover, several studies have shown that GAS6 may be involved in metastasis of several types of cancer, including prostate, renal cell, pancreatic, and breast cancer. $^{21,29-32}$

The underlying mechanisms of GAS6-regulated cell migration and invasion include JNK/ERK1/2, SRC, and AKT/GSK-3 $\beta / \beta$-catenin pathways. ${ }^{21,30,32}$ In our study, we found that GAS6 knockdown inhibited proliferation, migration, and invasion of $\mathrm{BCa}$ cells. To investigate the mechanisms of GAS6 in tumor progression, KEGG analyses were performed and showed that GAS6/TAM may be involved in the regulation of downstream PI3K/AKT signaling pathways. Furthermore, TCGA database analysis also showed that high expression of GAS6 was significantly associated with PI3K expression. In addition, we found that the protein levels of PI3K and p-AKT were significantly decreased by GAS6 knockdown. Treatment of BCa cells with SC79, an AKT activator, partially restored the effect of GAS6 silencing on cell proliferation and invasion. These results have shown that GAS6 may modulate PI3K-AKT signaling to regulate the proliferation and invasion of $\mathrm{BCa}$ cells.

\section{Conclusions}

Our study demonstrates that GAS6 is overexpressed in $\mathrm{BCa}$ cells. High levels of GAS6 expression are associated with tumor stage and grade, poor OS, and is a potential prognostic marker for $\mathrm{BCa}$. In addition, we show that GAS6 plays a pivotal role in the proliferation, migration, and invasion of BCa cells by activating PI3K-AKT signaling. Therefore, GAS6 may serve as a novel prognostic marker for $\mathrm{BCa}$ patients and might be a potential target for the treatment of $\mathrm{BCa}$.

\section{Ethical Statement}

All procedures performed in studies involving human participants were in accordance with the ethical standards of Shanghai Tenth People's Hospital of Tongji University (number: SHSY-IEC-4.1/19-120/01) and with the 1964 Helsinki declaration and its later amendments or comparable ethical standards. Informed consent was obtained from all individual participants included in the study. This study was performed following the institutional and national guidelines and regulations of the Animal Protection and Use Committee and approved by the Ethics Committee of Shanghai Tenth People's Hospital of Tongji University (SHDSYY-2019-3028).

\section{Author Contributions}

All authors contributed to data analysis, drafting and revising the article, gave final approval of the version to be published, and agree to be accountable for all aspects of the work.

\section{Disclosure}

The authors declare that they have no conflicts of interest in this work.

\section{References}

1. Antoni S, Ferlay J, Soerjomataram I, et al. Bladder cancer incidence and mortality: a global overview and recent trends. Eur Urol. 2017;71 (1):96-108. doi:10.1016/j.eururo.2016.06.010

2. Burger M, Catto JW, Dalbagni G, et al. Epidemiology and risk factors of urothelial bladder cancer. Eur Urol. 2013;63:234-241. doi:10.1016/ j.eururo.2012.07.033

3. Sylvester RJ, van der Meijden AP, Oosterlinck W, et al. Predicting recurrence and progression in individual patients with stage Ta T1 bladder cancer using EORTC risk tables: a combined analysis of 2596 patients from seven EORTC trials. Eur Urol. 2006;49:466-5; discussion 75-7. doi:10.1016/j.eururo.2005.12.031

4. Huguet J. Follow-up after radical cystectomy based on patterns of tumor recurrence and its risk factors $\square$. Actas Urol Esp. 2013;37:376-382. doi:10.1016/j.acuro.2013.01.005

5. Ghoneim M, Abdel-Latif MM, El-Mekresh M, et al. Radical cystectomy for carcinoma of the bladder: 2720 consecutive cases 5 years later. J Urol. 2008;180(1):121-127. doi:10.1016/j.juro.2008.03.024

6. Siegel RL, Miller KD, Jemal A. Cancer statistics, 2018. CA Cancer J Clin. 2018;68:7-30. doi:10.3322/caac.21442 
7. Takako S, Knyazev PG, Clout NJ, et al. Structural basis for Gas6-Axl signalling. EMBO J. 2014;25:80-87. doi:10.1038/sj.emboj.7600912

8. Ammoun S, Provenzano L, Zhou L, et al. Axl/Gas6/NFkB signalling in schwannoma pathological proliferation, adhesion and survival. Oncogene. 2013;33:336-346. doi:10.1038/onc.2012.587

9. Song X, Wang H, Logsdon CD, et al. Overexpression of receptor tyrosine kinase Axl promotes tumor cell invasion and survival in pancreatic ductal adenocarcinoma. Cancer. 2011;117(4):734-743. doi:10.1002/cncr.25483

10. Demarest SJ, Gardner J, Vendel MC, et al. Evaluation of Tyro3 expression, Gas6-mediated Akt phosphorylation, and the impact of anti-Tyro3 antibodies in melanoma cell lines. Biochemistry. 2013;52:3102-3118. doi:10.1021/bi301588c

11. Gustafsson A, Boström A-K, Ljungberg B, et al. Gas6 and the receptor tyrosine kinase Axl in clear cell renal cell carcinoma. PLoS One. 2009;4:e7575. doi:10.1371/journal.pone.0007575

12. Sainaghi PP, Castello L, Bergamasco L, et al. Gas6 induces proliferation in prostate carcinoma cell lines expressing the Axl receptor. J Cell Physiol. 2005;204:36-44. doi:10.1002/jcp.20265

13. Hattori S, Kikuchi E, Kosaka T, et al. Relationship between increased expression of the Ax1/Gas6 signal cascade and prognosis of patients with upper tract urothelial carcinoma. Ann Surg Oncol. 2016;23 (2):1-8. doi:10.1245/s10434-015-4848-x

14. Lee C-H, Yen CY, Liu SY, et al. Axl is a prognostic marker in oral squamous cell carcinoma. Ann Surg Oncol. 2012;19(Suppl 3):S500. doi:10.1245/s10434-011-1985-8

15. Ishikawa M, Sonobe M, Nakayama E, et al. Higher expression of receptor tyrosine kinase Axl, and differential expression of its ligand, Gas6, predict poor survival in lung adenocarcinoma patients. Ann Surg Oncol. 2013;20(S3):S467-S76. doi:10.1245/s10434-012-2795-3

16. Gustafsson A, Martuszewska D, Johansson M, et al. Differential expression of Axl and Gas6 in renal cell carcinoma reflecting tumor advancement and survival. Clin Cancer Res. 2009;15(14):4742. doi:10.1158/1078-0432.CCR-08-2514

17. Zhang W, Zhang J, Zhang Z, et al. Overexpression of indoleamine 2,3-dioxygenase 1 promotes epithelial-mesenchymal transition by activation of the IL-6/STAT3/PD-L1 pathway in bladder cancer. Transl Oncol. 2019;12(3):485-492. doi:10.1016/j.tranon.2018.11.012

18. Lew ED, Oh J, Burrola PG, et al. Differential TAM receptor-ligandphospholipid interactions delimit differential TAM bioactivities. Elife. 2014;3. doi:10.7554/eLife.03385

19. Zhang Y, Tang YJ, Man Y, et al. Knockdown of AXL receptor tyrosine kinase in osteosarcoma cells leads to decreased proliferation and increased apoptosis. Int $J$ Immunopathol Pharmacol. 2013;26:179-188. doi:10.1177/039463201302600117
20. Loges S, Schmidt T, Tjwa M, et al. Malignant cells fuel tumor growth by educating infiltrating leukocytes to produce the mitogen Gas6. Blood. 2010;115(11):2264-2273. doi:10.1182/blood-2009-06-228684

21. Lee Y, Lee M, Kim S. Gas6 induces cancer cell migration and epithelial-mesenchymal transition through upregulation of MAPK and Slug. Biochem Biophys Res Commun. 2013;434:8-14. doi:10.1016/j.bbrc.2013.03.082

22. Markus H, Pjotr K, Ariane A, et al. Axl and growth arrest-specific gene 6 are frequently overexpressed in human gliomas and predict poor prognosis in patients with glioblastoma multiforme. Clin Cancer Res. 2007;14:130-138. doi:10.1158/1078-0432.CCR-07-0862

23. Ito M, Nakashima M, Nakayama T, et al. Expression of receptor-type tyrosine kinase, Axl, and its ligand, Gas6, in pediatric thyroid carcinomas around chernobyl. Thyroid. 2002;12(11):971-975. doi:10.1089/ 105072502320908303

24. Mc Cormack O, Chung WY, Fitzpatrick P, et al. Growth arrest-specific gene 6 expression in human breast cancer. $\mathrm{Br}$ J Cancer. 2008;98(6):1141-1146. doi:10.1038/sj.bjc.6604260

25. Patel PG, Wessel T, Kawashima A, et al. A three-gene DNA methylation biomarker accurately classifies early stage prostate cancer. Prostate. 2019;79(14):1705-1714. doi:10.1002/pros.23895

26. Bester AC, Lee JD, Chavez A, et al. An integrated genome-wide CRISPRa approach to functionalize lncRNAs in drug resistance. Cell. 2018;173(3):649-664.e20. doi:10.1016/j.cell.2018.03.052

27. Lee $\mathrm{CH}$, Chu NF, Shieh YS, et al. The growth arrest-specific 6 (Gas6) gene polymorphism c.834+7G $>\mathrm{A}$ is associated with type 2 diabetes. Diabetes Res Clin Pract. 2012;95(2):201-206. doi:10.1016/j. diabres.2011.09.013

28. Rui X, Wang L, Pan H, et al. LncRNA GAS6-AS2 promotes bladder cancer proliferation and metastasis via GAS6-AS2/miR-298/CDK9 axis. J Cell Mol Med. 2019;23(2):865-876. doi:10.1111/jemm.13986

29. Yusuke S, Pedersen EA, Patel LR, et al. GAS6/AXL axis regulates prostate cancer invasion, proliferation, and survival in the bone marrow niche. Neoplasia. 2010;12:116,IN4-27,IN4. doi:10.1593/ neo.91384

30. Xiao Y, Zhao H, Tian L, et al. S100A10 is a critical mediator of GAS6/AXL-induced angiogenesis in renal cell carcinoma. Cancer Res. 2019;79(22):5758-5768. doi:10.1158/0008-5472.CAN-19-1366

31. Kirane A, Ludwig KF, Sorrelle N, et al. Warfarin blocks Gas6-mediated Axl activation required for pancreatic cancer epithelial plasticity and metastasis. Cancer Res. 2015;75(18):3699-3705. doi:10.1158/0008-5472.CAN-14-2887-T

32. Wang $\mathrm{C}$, Jin H, Wang N, et al. Gas6/Axl Axis contributes to chemoresistance and metastasis in breast cancer through Akt/GSK-3 $\beta / \beta$ catenin signaling. Theranostics. 2016;6(8):1205-1219. doi:10.7150/ thno. 15083
OncoTargets and Therapy

\section{Publish your work in this journal}

OncoTargets and Therapy is an international, peer-reviewed, open access journal focusing on the pathological basis of all cancers, potential targets for therapy and treatment protocols employed to improve the management of cancer patients. The journal also focuses on the impact of management programs and new therapeutic

\section{Dovepress}

agents and protocols on patient perspectives such as quality of life, adherence and satisfaction. The manuscript management system is completely online and includes a very quick and fair peer-review system, which is all easy to use. Visit http://www.dovepress.com/ testimonials.php to read real quotes from published authors. 